\title{
A survey tool for measuring evidence-based decision making capacity in public health agencies
}

Julie A Jacobs ${ }^{1}$, Paula F Clayton², Cassandra Dove ${ }^{3}$, Tanya Funchess ${ }^{4}$, Ellen Jones ${ }^{5}$, Ghazala Perveen ${ }^{2}$, Brandon Skidmore ${ }^{2}$, Victor Sutton ${ }^{3}$, Sarah Worthington ${ }^{6}$, Elizabeth A Baker ${ }^{7}$, Anjali D Deshpande ${ }^{8}$ and Ross C Brownson ${ }^{1,9,10^{*}}$

\begin{abstract}
Background: While increasing attention is placed on using evidence-based decision making (EBDM) to improve public health, there is little research assessing the current EBDM capacity of the public health workforce. Public health agencies serve a wide range of populations with varying levels of resources. Our survey tool allows an individual agency to collect data that reflects its unique workforce.
\end{abstract}

Methods: Health department leaders and academic researchers collaboratively developed and conducted crosssectional surveys in Kansas and Mississippi (USA) to assess EBDM capacity. Surveys were delivered to state- and local-level practitioners and community partners working in chronic disease control and prevention. The core component of the surveys was adopted from a previously tested instrument and measured gaps (importance versus availability) in competencies for EBDM in chronic disease. Other survey questions addressed expectations and incentives for using EBDM, self-efficacy in three EBDM skills, and estimates of EBDM within the agency.

Results: In both states, participants identified communication with policymakers, use of economic evaluation, and translation of research to practice as top competency gaps. Self-efficacy in developing evidence-based chronic disease control programs was lower than in finding or using data. Public health practitioners estimated that approximately two-thirds of programs in their agency were evidence-based. Mississippi participants indicated that health department leaders' expectations for the use of EBDM was approximately twice that of co-workers' expectations and that the use of EBDM could be increased with training and leadership prioritization.

Conclusions: The assessment of EBDM capacity in Kansas and Mississippi built upon previous nationwide findings to identify top gaps in core competencies for EBDM in chronic disease and to estimate a percentage of programs in U.S. health departments that are evidence-based. The survey can serve as a valuable tool for other health departments and non-governmental organizations to assess EBDM capacity within their own workforce and to assist in the identification of approaches that will enhance the uptake of EBDM processes in public health programming and policymaking. Localized survey findings can provide direction for focusing workforce training programs and can indicate the types of incentives and policies that could affect the culture of EBDM in the workplace.

Keywords: Evidence-based practice, Public health

\footnotetext{
* Correspondence: rbrownson@wustl.edu

'Prevention Research Center in St. Louis, Brown School, Washington

University in St. Louis, St. Louis, MO, USA

Full list of author information is available at the end of the article
} 


\section{Background}

Chronic diseases, such as heart disease, cancer and diabetes, are responsible for about $60 \%$ of all deaths globally and $70 \%$ of deaths in the United States [1,2] with morbidity and mortality projected to increase both nationally and internationally over the next several decades [1,3]. Physical inactivity, poor diet, tobacco use, alcohol consumption, and other modifiable behavioral risk factors account for a substantial number of these deaths $[4,5]$, allowing ample intervention opportunities through public health programs and policies.

Calls for the use of evidence-based decision making (EBDM) processes to develop chronic disease control and prevention programs come from both academia and practice, including major health organizations such as the World Health Organization and the Centers for Disease Control and Prevention [6-10]. The concept of EBDM in public health has evolved over the past decade and can be summarized as a process that utilizes the best available scientific evidence regarding the effectiveness of various programs or policies and translates that evidence to real world practice by incorporating community-level data, resources, and priorities [11,12].

There is a well-recognized gap between the production of scientific evidence and the use of that evidence in "real world" settings [13-16] (e.g., policy making bodies, health departments). Closing the translation gap is a complicated process, and increasing amounts of literature address this topic, often referred to as "knowledge transfer" or "dissemination and implementation research" [13-16]. The use of EBDM in public health agencies depends on many factors, including the training and experience of the workforce, organizational resources and climate (e.g., funding, buy-in from leadership and elected officials), and the availability, applicability, and dissemination of evidence on a given topic [16-21].

Research is needed to understand the determinants and approaches that will enhance the uptake of EBDM processes in public health agencies. We conducted a two phase research project that aimed to increase the use of chronic disease evidence-based interventions (EBIs) in public health agency settings. In the first phase, 447 state-level chronic disease practitioners across the U.S. completed a survey that assessed the importance, availability, and use of various components of EBDM in chronic disease. Through quantitative and qualitative methods, we examined practitioner's barriers and solutions to improving the use of EBIs in state health departments and assessed gaps in the importance and availability of core chronic disease competencies [22-24].

In phase 2, we conducted in-depth projects in two $U$. S. states: Kansas and Mississippi. Under the U.S. constitutional doctrine of reserved powers, the states retain enormous authority to protect the public's health [25]. The states shoulder their broad public health responsibilities through work carried out by state and local health agencies. These interventions are primarily focused on chronic disease prevention and control (primary and secondary prevention), not on management of chronic disease. Non-governmental organizations (NGOs) and other community partners also play critical roles in public health, providing health services and implementing interventions and policy changes in a variety of capacities.

There are large variations in the populations these agencies serve, their types of governance, the services they provide, and the education and job functions of their staff [26-30]. Due to this heterogeneity in public health agencies, it is important to have tools to collect localized data that reflect the unique nature of an agency's workforce and community partners [31]. We began phase 2 by developing a brief survey tool to assess baseline capacity for EBDM, seeking to identify specific targets for increasing the dissemination of EBIs in these two states. This article presents methods and findings from the initial phase 2 survey assessment with the goal of encouraging other public health agencies, in the U.S. and across the globe, to assess EBDM in their own workforce.

\section{Methods}

\section{State selection}

Kansas and Mississippi were chosen for this study based on their recent completion of a State Technical Assistance and Review (STAR) Program through the National Association of Chronic Disease Directors (NACDD) [32]. Seven states had completed the STAR program at the time of selection (September 2009), but for feasibility and resource reasons, only two were chosen for this study. The STAR process involved self-study by the state along with a four-day site visit by an experienced chronic disease control and prevention team. Prior to involvement in this research project, both Kansas and Mississippi had identified strengths, challenges and priorities of their chronic disease units, and they were beginning to implement recommendations from the STAR report. The STAR program recommends that states conduct ongoing assessment, and the current survey helped fulfill this function for Kansas and Mississippi.

\section{Kansas survey development}

The leader of the Kansas chronic disease unit selected a small team of health department employees to participate in this research project. The Kansas team consisted of the Director and Deputy Director of the Bureau of 
Health Promotion and the Director of Science and Surveillance/Health Officer II. Through monthly conference calls and email communications, the Kansas team and academic researchers collaboratively developed the survey instrument and sampling plan.

The majority of this cross-sectional survey was derived from the 74-question national survey used in the first phase of our study [22-24]. The content of that national survey was informed by previous work regarding a card sorting exercise that rated competencies for evidencebased cancer control [33], and the survey underwent cognitive response testing. The Kansas team customized job-related demographic questions (e.g., job title, program area specialty). Four new survey questions were added. Three addressed the self-efficacy of EBDM skills and one produced an estimate of evidence-based programs within one's agency. The Kansas survey contained 33 questions and was estimated to take less than 15 minutes to complete.

The Kansas team identified employees and partners who worked in chronic disease control and prevention. Kansas survey recipients included state and local health department practitioners as well as academic, coalition and volunteer community partners. In this decentralized state health department (SHD), state officials did not have access to complete contact lists for local health department (LHD) practitioners. Prior to the survey's launch, we contacted LHD directors from the 13 counties that served the largest populations and asked them to identify employees who worked in chronic disease control and prevention. The survey was initially delivered to all LHD directors and to the additional practitioners identified in those 13 counties. Using a snowball sampling technique, we also allowed all LHD survey respondents to identify colleagues who worked in chronic disease. After verifying their employment and excluding any duplicate names, we delivered the survey to those colleagues as well.

\section{Mississippi survey development}

Mississippi survey development followed the same process. The Mississippi team included the Director of the Office of Preventive Health, the Director and Deputy Director of the Chronic Disease Bureau, and an NACDD consultant. Demographic questions were customized and the 4 questions added to the Kansas survey were retained in the Mississippi survey. Due to concerns that respondents would consider topics such as immunizations and infectious disease when answering, the Mississippi survey repeated certain questions to ask first about all programs and then specifically about chronic disease programs.

The Mississippi team added a new question regarding expectations to use EBDM ("who expects you to use
EBDM related to public health program planning"). Participants could select boxes for health department leaders, direct supervisor, co-workers, and community partners. The Mississippi survey also added a question asking participants to choose their top 2 incentives for using EBDM in their work from the following list: 1) EBDM is given a high priority by leaders in my organization, 2) positive feedback or encouragement, 3) a performance evaluation that considers the use of EBDM, 4) trainings, and 5) professional recognition. The Mississippi survey contained 38 questions and was also designed to be completed in less than 15 minutes.

Survey recipients were identified by the Mississippi team and included state- and district-level public health practitioners. The Mississippi State Department of Health has a centralized relationship with local health departments, and the state is divided into nine districts that each oversee several county health departments.

\section{Data collection}

Prior to the survey distribution, an email co-written by a health department leader and the principal investigator of our research team explained the survey and its importance to each recipient on our contact list. The survey was delivered using ZipSurvey online survey software [34]. Each participant received a unique link to the survey, and nonrespondents received reminder emails. Because incentives increase response rates [35], we offered a $\$ 10$ gift card to each participant who completed the survey. The Kansas survey was open for 9 weeks from December 2009 to February 2010, and Mississippi's survey was open for 6 weeks from January to March 2010. The survey instruments are available from the last author and in Additional Files 1 and 2 of this manuscript. This study was approved by the Washington University Human Research Protection Office (HRPO \#09-1745).

\section{Analysis}

Respondents who answered only demographic questions were not included in descriptive summaries or in response rates. Bivariate relationships were analyzed using independent samples t-tests or Pearson chi-square tests. For the EBDM competencies (see Additional Files 1 and 2 for descriptions), respondents rated both the importance and the availability of the competencies on a scale of 0 (very unimportant or unavailable) to 10 (very important or available). The survey defined availability as "how available you feel each skill is to you when you need it (either in your own skill set or in others')" while importance was not further defined. We created a gap score by subtracting each availability score from the corresponding importance score and calculated a 95\% confidence interval (CI) for each. 


\section{Results}

The Kansas survey was delivered to 391 valid email addresses and received 190 responses, yielding a 49\% response rate. Survey responses were nearly evenly split among SHD practitioners (36\%), LHD practitioners (33\%) and community partners (31\%) (Table 1). Over half (55\%) had more than 10 years of experience in public health, and $49 \%$ indicated that they held a master's or doctoral degree.

The Mississippi survey had a $75 \%$ response rate with 72 surveys completed out of the 96 delivered. State practitioners represented $56 \%$ of the responses, and the remaining $44 \%$ were from district health offices. The majority of respondents (72\%) had more than 10 years of public health experience, and over half (56\%) held a master's or doctoral degree.

Nearly $80 \%$ of respondents were female in both Kansas and Mississippi. Also in both surveys, practitioners at the state level were significantly more likely to hold master's or doctoral degrees than those at the local or district level (Kansas $\mathrm{p}=0.03$, Mississippi $\mathrm{p}<0.01$ ). In Kansas, the largest job categories represented were program managers, administrators or coordinators (48\%) and health educators (15\%). In Mississippi, over a third of the respondents were nurses (35\%) while this group represented less than 7\% of Kansas' responses.

In both Kansas and Mississippi, the three biggest gaps between the importance and the availability of competencies necessary for EBDM in chronic disease were: transmitting evidence-based research to policymakers,

Table 1 Participants in evidence-based decision making capacity surveys in Kansas and Mississippi, USA, 2010

\begin{tabular}{lcc}
\hline & Kansas $\boldsymbol{n}$ (\%) & $\begin{array}{c}\text { Mississippi } \boldsymbol{n} \\
\text { (\%) }\end{array}$ \\
\hline $\begin{array}{l}\text { Agency } \\
\text { State Health Department }\end{array}$ & $69(36.3)$ & $40(55.6)$ \\
$\quad$ Local/District Health & $63(33.2)$ & $32(44.4)$ \\
$\quad \begin{array}{l}\text { Department } \\
\text { Community Partners }\end{array}$ & $58(30.5)$ & \\
\hline Most Advanced Degree & & \\
$\quad$ Doctorate or Master's & $93(48.9)$ & $41(56.9)$ \\
$\quad$ Bachelors or Some College & $88(46.3)$ & $31(43.1)$ \\
$\quad$ Missing & $9 .(4.7)$ & \\
\hline Years of Public Health Experience & & \\
$\quad$ < years & $38(20.0)$ & $8(11.1)$ \\
5 to < 10 years & $45(23.7)$ & $12(16.7)$ \\
10+ years & $104(54.7)$ & $52(72.2)$ \\
$\quad$ Missing & $3(1.6)$ & \\
\hline Gender & & \\
Female & $151(79.5)$ & $56(77.8)$ \\
Male & $38(20.0)$ & $15(20.8)$ \\
Missing & $1(0.5)$ & $1(1.4)$ \\
\hline
\end{tabular}

making decisions based on economic evaluation, and translating evidence-based interventions to "real world" settings (Table 2). In Kansas, mean importance and availability scores were higher for state respondents compared to local respondents, and gaps were larger at the local level than at the state level. Mississippi surveys showed more mixed results, and gap scores were larger at the state level compared to the district level.

Across all four categories, the percentage of Mississippi respondents who agreed that each expected them to use EBDM was higher for all programs compared to chronic disease programs (Table 3 ). In both categories, the highest percentage of respondents agreed that health department leaders expect them to use EBDM and the lowest percentage was among co-workers. Mississippi participants indicated that their overall top choices of incentive for using EBDM were: trainings and leaders in their organization placing a high priority on EBDM (Table 4). Those in the state office were more likely to prefer high priority among leadership.

The highest rated skill in both surveys was the ability to find data (Kansas mean 7.4, 95\%CI 7.1-7.8; Mississippi mean $8.0,95 \%$ CI 7.4-8.5). The ability to use data for public health programming, grant writing or community assessment followed (Kansas mean 7.0, 95\% CI 6.7-7.4; Mississippi mean 7.3, 95\%CI 6.7-7.9) with developing evidence-based chronic disease programs as the lowest rated skill (Kansas mean 6.3, 95\%CI 6.0-6.6; Mississippi mean 6.6, 95\%CI 6.2-7.1).

Estimates of the percentage of evidence-based programs among all respondents from health departments were similar between Kansas and Mississippi. Kansas health department employees' mean estimate of the percentage of evidence-based programs in their agency was 65\% (95\%CI 61-70\%). Mississippi survey respondents' overall mean estimate was 67\% (95\%CI 60-73\%). Median estimates for both Kansas and Mississippi were $75 \%$.

\section{Discussion}

Despite increasing calls internationally for the inclusion of EBDM processes in public health programming, policymaking, and strategic planning [6-10,36-41], there is relatively sparse research to assess the workforce's current capacity at the local level. One notable exception is a needs assessments of population health staff conducted in New South Wales, Australia [42,43]. Their studies identified needs for technical support, training, and skills development, particularly among practitioners without master's degrees. The majority (55\%) of practitioners recognized the need to increase their own capacity for EBDM. Practitioners indicated that their managers had more positive views than their own on the current promotion of evidence-based practice in population health while colleagues' views were less 
Table 2 Importance, availability, and gaps in competency ratings ${ }^{\ddagger}$, Kansas and Mississippi, USA, 2010

\begin{tabular}{|c|c|c|c|c|c|c|}
\hline \multirow[b]{2}{*}{ Competency } & \multicolumn{3}{|c|}{ Kansas $n=190$} & \multicolumn{3}{|c|}{ Mississippi $n=72$} \\
\hline & $\begin{array}{c}\text { All } \\
\text { respondents }\end{array}$ & $\begin{array}{l}\text { State health } \\
\text { department }\end{array}$ & $\begin{array}{l}\text { Local health } \\
\text { department }\end{array}$ & $\begin{array}{c}\text { All } \\
\text { respondents }\end{array}$ & $\begin{array}{l}\text { State health } \\
\text { department }\end{array}$ & $\begin{array}{c}\text { District health } \\
\text { department }\end{array}$ \\
\hline \multicolumn{7}{|c|}{ Mean (95\% Confidence Interval) } \\
\hline \multicolumn{7}{|c|}{ Transmitting Research to Policymakers } \\
\hline Importance & $8.8(8.6-9.0)$ & $9.1(8.8-9.4)$ & $8.4(8.0-8.8)^{* * *}$ & $8.7(8.2-9.1)$ & $9.1(8.6-9.5)$ & $8.1(7.4-8.8)^{* *}$ \\
\hline Availability & $5.1(4.8-5.5)$ & $5.5(4.9-6.1)$ & $4.3(3.8-4.9)^{* * *}$ & $5.3(4.7-5.9)$ & $5.4(4.6-6.2)$ & $5.0(4.1-6.0)$ \\
\hline Gap & $3.7(3.4-4.1)$ & $3.6(3.0-4.2)$ & $4.1(3.4-4.7)$ & $3.4(2.8-4.0)$ & $3.6(2.7-4.6)$ & $3.1(2.2-3.9)$ \\
\hline \multicolumn{7}{|c|}{ Decisions Based on Economic Evaluation } \\
\hline Importance & $8.5(8.3-8.7)$ & $8.7(8.3-9.0)$ & $8.2(7.8-8.6)$ & $8.8(8.5-9.2)$ & $9.0(8.6-9.4)$ & $8.5(8.0-9.1)$ \\
\hline Availability & $5.1(4.8-5.5)$ & $5.4(4.8-6.0)$ & $4.6(4.0-5.3)^{*}$ & $5.6(5.0-6.2)$ & $5.4(4.5-6.2)$ & $6.0(5.1-6.9)$ \\
\hline Gap & $3.4(3.1-3.7)$ & $3.3(2.7-3.8)$ & $3.6(3.0-4.2)$ & $3.2(2.5-3.9)$ & $3.7(2.7-4.6)$ & $2.5(1.7-3.4)^{*}$ \\
\hline \multicolumn{7}{|c|}{ Translating Evidence-Based Interventions } \\
\hline Importance & $8.7(8.4-8.9)$ & $9.1(8.8-9.4)$ & $8.0(7.4-8.5)^{* * *}$ & $9.1(8.8-9.4)$ & $9.4(9.0-9.7)$ & $8.8(8.4-9.1)^{* *}$ \\
\hline Availability & $5.5(5.2-5.9)$ & $6.0(5.5-6.6)$ & $4.7(4.1-5.3)^{* * *}$ & $5.6(5.0-6.2)$ & $5.8(4.9-6.6)$ & $5.4(4.4-6.3)$ \\
\hline Gap & $3.1(2.8-3.5)$ & $3.0(2.4-3.6)$ & $3.2(2.7-3.8)$ & $3.5(2.8-4.1)$ & $3.6(2.7-4.4)$ & $3.4(2.4-4.3)$ \\
\hline \multicolumn{7}{|l|}{$\begin{array}{l}\text { Qualitative } \\
\text { Evaluation }\end{array}$} \\
\hline Importance & $8.0(7.7-8.2)$ & $8.4(8.1-8.7)$ & $7.3(6.8-7.8)^{* * *}$ & $8.6(8.3-8.9)$ & $8.9(8.5-9.3)$ & $8.2(7.7-8.7)^{* *}$ \\
\hline Availability & $5.5(5.1-5.8)$ & $5.9(5.4-6.5)$ & $4.4(3.7-5.0)^{* * *}$ & $5.8(5.1-6.4)$ & $6.0(5.1-6.9)$ & $5.4(4.6-6.3)$ \\
\hline Gap & $2.5(2.2-2.8)$ & $2.5(2.0-3.0)$ & $2.9(2.4-3.5)$ & $2.9(2.2-3.5)$ & $2.9(2.0-3.8)$ & $2.8(1.9-3.6)$ \\
\hline \multicolumn{7}{|c|}{ Developing an Action Plan for Program/Policy } \\
\hline Importance & $8.7(8.4-8.9)$ & $9.0(8.6-9.3)$ & $8.2(7.7-8.7)^{* * *}$ & $9.0(8.7-9.3)$ & $9.2(8.8-9.6)$ & $8.7(8.3-9.2)$ \\
\hline Availability & $6.2(5.8-6.6)$ & $6.9(6.3-7.4)$ & $5.1(4.4-5.7)^{* * *}$ & $6.0(5.3-6.6)$ & $6.2(5.4-7.0)$ & $5.7(4.7-6.7)$ \\
\hline Gap & $2.5(2.2-2.8)$ & $2.1(1.6-2.6)$ & $3.1(2.5-3.7)^{* *}$ & $3.0(2.4-3.7)$ & $3.0(2.2-3.9)$ & $3.0(2.1-4.0)$ \\
\hline \multicolumn{7}{|c|}{ Multidisciplinary Partnerships } \\
\hline Importance & $8.9(8.7-9.1)$ & $9.1(8.7-9.4)$ & $8.6(8.2-9.0)^{*}$ & $8.9(8.6-9.3)$ & $9.2(8.9-9.6)$ & $8.5(7.9-9.2)^{*}$ \\
\hline Availability & $6.2(5.8-6.5)$ & $6.8(6.2-7.3)$ & $5.7(5.1-6.3)^{* *}$ & $6.2(5.6-6.8)$ & $6.2(5.3-7.0)$ & $6.2(5.3-7.1)$ \\
\hline Gap & $2.7(2.4-3.1)$ & $2.3(1.7-2.9)$ & $2.9(2.3-3.5)$ & $2.7(2.2-3.3)$ & $3.0(2.2-3.9)$ & $2.3(1.6-3.1)$ \\
\hline \multicolumn{7}{|c|}{ Evaluation Designs } \\
\hline Importance & $7.4(7.1-7.7)$ & $7.9(7.5-8.2)$ & $6.4(5.9-7.0)^{* * *}$ & & & \\
\hline Availability & $4.9(4.6-5.3)$ & $5.4(4.9-5.9)$ & $3.8(3.2-4.4)^{* * *}$ & & & \\
\hline Gap & $2.5(2.1-2.8)$ & $2.5(2.0-2.9)$ & $2.6(2.1-3.2)$ & & & \\
\hline \multicolumn{7}{|c|}{ Quantitative Evaluation } \\
\hline Importance & $8.2(7.9-8.4)$ & $8.5(8.2-8.9)$ & $7.4(6.9-7.9)^{* * *}$ & $8.2(7.8-8.6)$ & $8.5(8.0-9.1)$ & $7.8(7.0-8.5)^{*}$ \\
\hline Availability & $5.9(5.5-6.3)$ & $6.7(6.2-7.2)$ & $4.4(3.8-5.1)^{* * *}$ & $5.8(5.2-6.4)$ & $6.0(5.2-6.8)$ & $5.6(4.6-6.5)$ \\
\hline Gap & $2.3(1.9-2.6)$ & $1.8(1.4-2.3)$ & $3.0(2.4-3.5)^{* * *}$ & $2.4(1.8-2.9)$ & $2.5(1.8-3.3)$ & $2.2(1.4-3.0)$ \\
\hline \multicolumn{7}{|c|}{ Prioritizing Health Issues } \\
\hline Importance & $8.3(8.0-8.5)$ & $8.6(8.2-8.9)$ & $7.8(7.4-8.2)^{* * *}$ & $8.4(8.0-8.8)$ & $8.6(7.9-9.2)$ & $8.2(7.6-8.7)$ \\
\hline Availability & $6.1(5.8-6.4)$ & $6.4(5.9-6.8)$ & $5.3(4.7-5.9)^{* *}$ & $5.9(5.3-6.4)$ & $5.7(4.9-6.4)$ & $6.1(5.3-6.9)$ \\
\hline$\overline{\text { Gap }}$ & $2.2(1.9-2.5)$ & $2.2(1.8-2.6)$ & $2.5(2.0-3.0)$ & $2.5(2.0-3.1)$ & $2.9(2.2-3.7)$ & $2.1(1.3-2.8)$ \\
\hline
\end{tabular}

\# Likert scale 0-10 with higher scores indicating greater importance/availability state vs. local/district health departments: ${ }^{*} \mathrm{p}$ value $\leq 0.10 ;{ }^{* *} \mathrm{p}$ value $\leq 0.05 ;{ }^{* * *}$ $\mathrm{p}$ value $\leq 0.01$

positive than their own. Based on this needs assessment, a working group identified evidence-based practice competencies [44]. Additionally, recent U.S. public health systems research seeks to better understand the variability in the quality and availability of public health services and to identify approaches that will improve service delivery, including the increased use of EBDM in agency settings [28-30].

As part of our study to increase EBDM capacity in U. S. public health agencies, we developed tailored survey 
Table 3 Expectations to use evidence-based decision making ( $\mathbf{n}=72$ ), Mississippi, USA, 2010

\begin{tabular}{lcccc}
\hline & Total & State Office & District Office & $\mathbf{p}^{*}$ \\
\hline All Programs & & & & \\
\hline Health Dept. Leaders & $75 \%$ & $74 \%$ & $77 \%$ & .78 \\
\hline Direct Supervisor & $60 \%$ & $66 \%$ & $53 \%$ & .30 \\
\hline Community Partners & $59 \%$ & $55 \%$ & $63 \%$ & .50 \\
\hline Co-workers & $40 \%$ & $45 \%$ & $33 \%$ & .34 \\
\hline Chronic Disease Programs & & & & \\
\hline Health Dept. Leaders & $65 \%$ & $68 \%$ & $60 \%$ & .47 \\
\hline Direct Supervisor & $50 \%$ & $61 \%$ & $37 \%$ & .05 \\
\hline Community Partners & $52 \%$ & $55 \%$ & $47 \%$ & .48 \\
\hline Co-workers & $29 \%$ & $37 \%$ & $20 \%$ & .13 \\
\hline
\end{tabular}

${ }^{*} \mathrm{p}$ value for Pearson chi-square testing differences between state and district offices

tools to assess baseline EBDM capacity in two U.S. states. The core of our surveys was adopted from a previously testing instrument [22-24] and focused on practitioners' assessments of competencies previously determined to be critical to EBDM in chronic disease [33]. The practice of EBDM requires a broad skill set that includes the analysis and synthesis of evidence, quantitative and qualitative community assessments, and the use of program-planning frameworks [6]. The public health workforce is transdisciplinary by nature, and many who work in the field have no formal training in public health [45-47]. State-level practitioners in phase 1 of our study indicated that a lack of training necessary to conduct EBDM existed among both staff and managers [22]. Continued workforce training and capacity building is necessary, and the use of competencies to guide those efforts is critical for defining educational goals and outcomes $[47,48]$.

Identification of the largest gaps in EBDM competencies within a state or locality provides health department leaders with actionable targets for the improvement of EBDM capacity. The three largest competency gaps in the Kansas and Mississippi surveys were consistent with findings from our national survey of state-level chronic disease practitioners [24] and may translate to other states. Our research shows that practitioners identify important targets for improving EBDM as: 1) communication with policymakers, 2) use of economic evaluation, and 3) translation of research to practice. These are skills that practitioners identify as important, yet unavailable, and such skills can be improved through trainings and technical support [49]. Because all of the competencies included on the survey are considered high or medium priority from previous research [33], agencies may also want to provide trainings for those competencies with low availability scores or may consider the use of incentives or priority-setting to improve competencies with low importance scores. Evidencebased public health trainings, based on these key EBDM competencies, have been found to be effective methods of integrating new knowledge and skills into the public health workforce [49-51]. As part of our research project, EBDM training courses were conducted in both Kansas and Mississippi to address gaps in competencies. While not attempted in our project, the use of knowledge brokers in Canada is another emerging and promising strategy for facilitating the translation of research to practice [52].

Practitioners in our surveys estimated that approximately two-thirds of programs in their agency were evidence-based. Mean estimates from Kansas (65\%) and Mississippi (67\%) were consistent with the 58\% and 65\% estimates obtained in follow-up surveys of EBDM training courses offered to public health professionals in Missouri and nationwide [49, unpublished data, Brownson]. Survey respondents were provided with a standard definition of EBDM before answering this question, but the results should still be interpreted with caution given they are self-reported and not objectively validated. In our qualitative results from phase 1 of this study, chronic disease practitioners identified a lack of consensus among practitioners regarding the precise meaning of the term 'evidence-based' as a barrier to the practice of EBDM [22]. The same program may be deemed 'evidence-based' by one practitioner and not another, and more objective measures are needed. A next logical step in this work is to compare self-reported data (e.g., on use of evidence-based interventions) with program reports (e.g., content analysis of grant applications).

Table 4 Incentives ranked as $1^{\text {st }}$ and within top 2 choices for using EBDM, Mississippi, USA 2010

\begin{tabular}{|c|c|c|c|c|c|c|}
\hline & \multicolumn{2}{|c|}{ Total $n=68$} & \multicolumn{2}{|c|}{ State Office $n=38$} & \multicolumn{2}{|c|}{ District Office $n=30$} \\
\hline & $1^{\text {st }}$ Choice & Top 2 & $1^{\text {st }}$ Choice & Top 2 & $1^{\text {st }}$ Choice & Top 2 \\
\hline Trainings & $28 \%$ & $57 \%$ & $24 \%$ & $58 \%$ & $33 \%$ & $57 \%$ \\
\hline EBDM High Priority & $37 \%$ & $53 \%$ & $45 \%$ & $58 \%$ & $27 \%$ & $47 \%$ \\
\hline Positive Feedback & $13 \%$ & $49 \%$ & $11 \%$ & $45 \%$ & $17 \%$ & $53 \%$ \\
\hline Performance Evaluation & $15 \%$ & $29 \%$ & $13 \%$ & $26 \%$ & $17 \%$ & $33 \%$ \\
\hline Professional Recognition & $7 \%$ & $12 \%$ & $8 \%$ & $13 \%$ & $7 \%$ & $10 \%$ \\
\hline
\end{tabular}


New questions on the Mississippi survey provided results worthy of inclusion in subsequent surveys. Although sample sizes were relatively small, the expectation to use EBDM was lower for chronic disease programs compared to all programs, and the expectation from health department leaders nearly doubled that of co-workers. Creating a culture of EBDM in chronic disease control and prevention that encompasses all job types and levels of management will be an important step in increasing the use of EBIs [6]. Practitioners in our nationwide survey identified a lack of incentives for using EBDM as the highest of nine quantitatively measured barriers [23], and the Mississippi survey explored preferences for a range of incentives. Among Mississippi's customized list of incentives, respondents preferred leaders placing a "high priority" on EBDM and the provision of EBDM trainings. Leadership buy-in is a critical first step in order for practitioners to be able to utilize the knowledge and skills gained from EBDM trainings.

This survey's biggest limitation was that data were self-reported. We cannot directly validate our findings against a gold standard. Furthermore, the response rate in both states was low, and non-response bias is possible. Nearly half (51\%) of Kansas recipients (a more diverse sample including community partners) and 25\% of Mississippi recipients did not complete the survey. People with strong opinions on EBDM, either positive or negative, may have been more likely to respond. Data were not available to compare respondents with nonrespondents across demographic characteristics. While this survey was created with ease of replication in mind, agencies with limited funds will not be able to offer gift cards incentives to increase response rates. Incentives for survey completion can take many forms, and agencies should use available resources.

\section{Conclusions}

Top competency gaps in Kansas and Mississippi reinforced findings from our previous nationwide survey [24], indicating that, overall, practitioners need more training and tools for transmitting research to policymakers, making decisions based on economic evaluations, and translating EBIs to "real world" settings. Using our survey tool, health departments and NGOs can assess the unique EBDM capacity within their own workforce and use the localized survey findings to identify specific action points that will strengthen their EBDM capacity. These can include training programs focused on specific EBDM skills or can focus on incentives and policies that could affect the organizational culture and climate in a workplace [53]. EBDM is being advocated in many countries and by many health organizations. Our survey methods should be useful across numerous parts of the globe for assessing EBDM capacity and identifying approaches that will enhance the EBDM processes in public health programming and policymaking.

\section{Additional material}

\author{
Additional file 1: Survey instrument used in Kansas \\ Additional file 2: Survey instrument used in Mississippi.
}

\section{Acknowledgements}

This work was funded through the Centers for Disease Control and Prevention grant \#5R18DP001139-02 (Improving Public Health Practice through Translation Research) and the Centers for Disease Control and Prevention's Prevention Research Centers Program contract U48/DP001903. The authors appreciate the assistance of Dr. Elizabeth Dodson and Lauren Carothers in developing and conducting these surveys.

\section{Author details}

${ }^{1}$ Prevention Research Center in St. Louis, Brown School, Washington University in St. Louis, St. Louis, MO, USA. ${ }^{2}$ Bureau of Health Promotion, Kansas Department of Health and Environment, Topeka, KS, USA. ${ }^{3}$ Office of Preventive Health, Mississippi State Department of Health, Jackson, MS, USA. ${ }^{4}$ Office of Tobacco Control, Mississippi State Department of Health, Jackson, MS, USA. ${ }^{5}$ School of Health Related Professions, University of Mississippi Medical Center, and National Association of Chronic Disease Directors, Jackson, MS, USA. ${ }^{6}$ Active Living KC, Kansas City Health Department, Kansas City, MO, USA. ${ }^{7}$ Prevention Research Center in St. Louis, Saint Louis University School of Public Health, St. Louis, MO, USA. ${ }^{8}$ Division of Health Behavior Research, Washington University School of Medicine, Washington University in St. Louis, St. Louis, MO, USA. 'Division of Public Health Sciences, Alvin J. Siteman Cancer Center, Washington University School of Medicine, St. Louis, MO, USA. ${ }^{10}$ George Warren Brown School of Social Work, Division of Public Health Sciences, School of Medicine, Washington University in St. Louis, Kingshighway Building 660 S. Euclid Campus, Box 8109, St. Louis, MO 63110, USA.

\section{Authors' contributions}

Study concept and design: EAB, ADD, RCB. Development of survey tool and data interpretation: all authors. Data collection: JAJ, SW. Manuscript drafting: JAJ. Study supervision: RCB. All authors read and approved the final manuscript.

\section{Competing interests}

The authors declare that they have no competing interests.

Received: 22 September 2011 Accepted: 9 March 2012

Published: 9 March 2012

\section{References}

1. World Health Organization: The global burden of disease: 2004 update. [http://www.who.int/healthinfo/global_burden_disease/ GBD_report_2004update_full.pdf].

2. Kung HC, Hoyert DL, Xu J, Murphy SL: Deaths: final data for 2005. Natl Vital Stat Rep 2008, 56:1-120.

3. Anderson $\mathrm{G}$, Horvath J: The growing burden of chronic disease in America. Public Health Rep 2004, 119(3):263-270.

4. Danaei G, Ding EL, Mozaffarian D, Taylor B, Rehm J, Murray CJ, Ezzati M: The preventable causes of death in the United States: comparative risk assessment of dietary, lifestyle, and metabolic risk factors. PLoS Med 2009, 6(4):e1000058.

5. Mokdad AH: Actual causes of death in the United States, 2000. JAMA 2004, 291(10):1238-1245.

6. Brownson RC, Baker EA, Leet TL, Gillespie KN, True WR: Evidence-Based Public Health. 2 edition. New York: Oxford University Press; 2011. 
7. Fielding JE, Briss PA: Promoting evidence-based public health policy: can we have better evidence and more action? Health Aff (Millwood) 2006, 25(4):969-978.

8. Wilson KM, Brady TJ, Lesesne C: on behalf of the NCCDPHP Work Group on Translation: an organizing framework for translation in public health: the knowledge to action framework. Prev Chronic Dis 2011, 8(2):1-7.

9. World Health Organization: 2008-2013 action plan for the global strategy for the prevention and control of noncommunicable diseases: prevent and control cardiovascular diseases, cancers, chronic respiratory diseases \& diabetes.[http://www.who.int/nmh/Actionplan-PC-NCD-2008.pdf].

10. Zaza S, Briss PA, Harris KW: The Guide to Community Preventive Services: What Works to Promote Health? New York: Oxford University Press; 2005.

11. Brownson RC, Fielding JE, Maylahn CM: Evidence-based public health: a fundamental concept for public health practice. Annu Rev Public Health 2009, 30:175-201.

12. Satterfield JM, Spring B, Brownson RC, Mullen EJ, Newhouse RP, Walker BB, Whitlock EP: Toward a transdisciplinary model of evidence-based practice. Milbank Quarterly 2009, 87(2):368-90.

13. Green LW, Ottoson JM, Garcia C, Hiatt RA: Diffusion theory and knowledge dissemination, utilization, and integration in public health. Annu Rev Public Health 2009, 30:151-74.

14. Graham IA, Logan J, Harrison MB, Straus SE, Tetroe J, Caswell W, Robinson N: Lost in knowledge translation: time for a map? J Contin Educ Health Prof 2006, 26:13-24.

15. Lavis JN: Research, public policymaking, and knowledge-translation processes: Canadian efforts to build bridges. J Contin Educ Health Prof 2006, 26:37-45.

16. Dobbins M, Ciliska D, Cockerill R, Barnsley J, DiCenso A: A framework for the dissemination and utilization of research for health-care policy and practice. Online J Knowl Synth Nurs 2002, 9(7)

17. Anderson LM, Brownson RC, Fullilove MT, Teutsch SM, Novick LF, Fielding J, Land GH: Evidence-based public health policy and practice: promises and limits. Am J Prev Med 2005, 28(Suppl 5):226-230.

18. Kerner JF: Integrating research, practice, and policy: what we see depends on where we stand. J Public Health Management Practice 2008, 14(2):193-198.

19. Baker EA, Brownson RC, Dreisinger M, McIntosh LD, Karamehic-Muratovic A: Examining the role of training in evidence-based public health: a qualitative study. Health Promot Pract 2009, 10:342-348.

20. Baker EL, Potter MA, Jones DL, Mercer SL, Cioffi JP, Green LW, Halverson PK, Lichtveld MY, Fleming DW: The public health infrastructure and our nation's health. Annu Rev Public Health 2005, 26:303-318.

21. Brownson RC, Ballew P, Dieffenderfer B, Haire-Joshu D, Heath GW, Kreuter MW, Myers BA: Evidence-based interventions to promote physical activity: what contributes to dissemination by state health departments. Am J Prev Med 2007, 33(Suppl 1):66-73.

22. Dodson EA, Baker EA, Brownson RC: Use of evidence-based interventions in state health departments: a qualitative assessment of barriers and solutions. J Public Health Manag Pract 2010, 16(6):E9-E15.

23. Jacobs JA, Dodson EA, Baker EA, Deshpande AD, Brownson RC: Barriers to evidence-based decision making in public health: a national survey of chronic disease practitioners. Public Health Rep 2010, 125:736-742.

24. Dodson EA: Personal and organizational barriers to evidence-based decision making among U.S. chronic disease practitioners. Presented at: Cultivating Health Communities: 20th National Conference on Chronic Disease Prevention and Control, Centers for Disease Control and Prevention National Harbor, MD; 2009.

25. McGowan A, Brownson R, Wilcox L, Mensah G: Prevention and control of chronic diseases. In In Law in Public Health Practice.. 2 edition. Edited by: Goodman R, Rothstein M, Hoffman R, Lopez W, Matthews G. New York: Oxford University Press; 2006:

26. National Association of County \& City Health Officials: 2008 National Profile of Local Health Departments.[http://www.naccho.org/topics/infrastructure/ profile/resources/2008report/upload/NACCHO_2008_ProfileReport_post-towebsite-2.pdf].

27. Association of State and Territorial Health Officials: Profile of state public health, volume two.[http://astho.org/uploadedFiles/_Publications/Files/ Survey_Research/ASTHO_State_Profiles_Single[1]\%20lo\%20res.pdf].

28. Mays GP, Scutchfield FD, Bhandari MW, Smith SA: Understanding the organization of public health delivery systems: an empirical typology. Milbank Q 2010, 88(1):81-111.
29. Mays GP, Smith SA, Ingram RC, Racster L, Lamberth CD, Lovely ES: Public health delivery systems: evidence, uncertainty, and emerging research needs. Am J Prev Med 2009, 36(3):256-65.

30. Van Wave TW, Scutchfield FD, Honore PA: Recent advances in public health systems research in the United States. Annu Rev Public Health 2010, 31:283-95.

31. Fielding JE, Frieden TR: Local knowledge to enable local action. Am J Prev Med 2004, 27(2):183-184.

32. National Association of Chronic Disease Directors: State technical assistance and review (STAR) program. [http://www.chronicdisease.org/? page $=$ STARFAQ].

33. Brownson RC, Ballew P, Kittur ND, Elliott MB, Haire-Joshu D, Krebill H, Kreuter MW: Developing competencies for training practitioners in evidence-based cancer control. J Cancer Educ 2009, 24:186-193.

34. ZipSurvey.com. [http://www.zipsurvey.com].

35. Dillman D: Mail and Internet Surveys: The Tailored Method. 2 edition. New York: Wiley; 2000.

36. Australian Health Promotion Association: Core competencies for health promotion practitioners.[http://www.healthpromotion.org.au/images/ stories/pdf/core\%20competencies\%20for\%20hp\%20practitioners.pdf].

37. Health Protection Agency: 2010 annual report and accounts.[http://www. hpa.org.uk/web/HPAwebFile/HPAweb_C/1274093575390].

38. Institute of Public Health in Ireland: IPH annual review: 2010.[http://www. publichealth.ie/sites/default/files/documents/files/IPH\%20Annual\%20Review \%202010.pdf].

39. Public Health Agency of Canada: Strategic plan 2007-2012.[http://www phac-aspc.gc.ca/publicat/2007/sp-ps/pdfs/PHAC_StratPlan_E_WEB.pdf].

40. Public Health Association Australia: Annual report 2009-2010 of the Public Health Association of Australia Incorporated.[http://www.phaa.net.au/ documents/110922\%20PHAA\%20Annual\%20Report\%20Final\%2010-11.pdf].

41. Robert Koch Institute: Report of the project group RKI 2010.[http://www. rki.de/cln_160/nn_1486290/EN/Content/Institute/RKI2010/RKI_2010, templateld=raw, property=publicationFile.pdf/RKI_2010.pdf].

42. Adily A, Ward J: Evidence based practice in population health: a regional survey to inform workforce development and organizational change. J Epidemiol Community Health 2004, 58:455-460.

43. Adily $\mathrm{A}$, Ward J: Enhancing evidence-based practice in population health: staff views, barriers and strategies for change. Aust Health Rev 2005, 29(4):469-477.

44. Maxwell ML, Adily A, Ward JE: Promoting evidence-based practice in population health the local level: a case study in workforce capacity development. Aust Health Rev 2007, 31(3):422-429.

45. Turnock BJ: Public Health: What It is and How It Works Sadbury, MA: Jones and Bartlett Publishers; 2009.

46. Gebbie KM: Public health certification. Annu Rev Public Health 2009, 30:203-10

47. Tilson H, Gebbie KM: The public health workforce. Annu Rev Public Health 2004, 25:341-356.

48. Koo D, Miner K: Outcome-based workforce development and education in public health. Annu Rev Public Health 2010, 31:253-69.

49. Dreisinger M, Leet TL, Baker EA, Gillespie KN, Haas B, Brownson RC: Improving the public health workforce: evaluation of a training course to enhance evidence-based decision making. J Public Health Manag Pract 2008, 14:138-143.

50. Brownson RC, Diem G, Grabauskas V, Legetic B, Potemkina R, Shatchkute A, Baker EA, Campbell CR, Leet TL, Nissinen A, Siegel PZ, Stachenko S, True WR, Waller M: Training practitioners in evidence-based chronic disease prevention for global health. Promot Educ 2007, 14(3):159-163.

51. Franks AL, Brownson RC, Bryant C, Brown KM, Hooker SP, Pluto DM, Shepard DM, Pate RR, Baker EA, Gillespie KN, Leet TL, O'Neall MA, Simoes J: Prevention Research Centers: contributions to updating the public health workforce through training. Prev Chronic Dis 2005, 2(2):A26.

52. Dobbins M, Roberson, Ciliska D, Hanna S, Cameron R, O'Mara L, DeCorby K, Mercer S: A description of a knowledge broker role implemented as part of a randomized controlled trial evaluating three knowledge translation strategies. Implement Sci 2009, 4:23.

53. Aarons G, Horowitz J, Dlugosz L, Ehrhart M: The role of organizational processes in dissemination and implementation research. In Dissemination and Implementation Research in Health: Translating Science to Practice. Edited by: Brownson RC, Colditz GA, Proctor EK. New York: Oxford University Press; 2012: 


\section{Pre-publication history}

The pre-publication history for this paper can be accessed here:

http://www.biomedcentral.com/1472-6963/12/57/prepub

doi:10.1186/1472-6963-12-57

Cite this article as: Jacobs et al:: A survey tool for measuring evidence-

based decision making capacity in public health agencies. BMC Health

Services Research 2012 12:57.

Submit your next manuscript to BioMed Central and take full advantage of:

- Convenient online submission

- Thorough peer review

- No space constraints or color figure charges

- Immediate publication on acceptance

- Inclusion in PubMed, CAS, Scopus and Google Scholar

- Research which is freely available for redistribution

Submit your manuscript at 